\title{
Características socioeconômicas da população e de seus representantes eleitos nas assembleias legislativas brasileiras: análise de convergência entre perfis
}

Cláudia Júlia Guimarães Horta

Fundação João Pinheiro (FJP)

Simone Cristina Dufloth

Fundação João Pinheiro (FJP)

Diego Roger Ramos Freitas

Fundação João Pinheiro (FJP)

O trabalho investiga a existência de relação de similaridade entre as características gerais dos representantes eleitos nas assembleias legislativas e o perfil demográfico e socioeconômico da população em idade de votar nas grandes regiões e nos estados brasileiros. O estudo analisa comparativamente o perfil dos representantes eleitos no que se refere às suas características gerais, ou seja, sexo, idade, nível de escolaridade e ocupação no período de 1998 a 2010, em relação às características gerais da população no que diz respeito à idade, sexo, nível educacional e nível de renda. Conclui-se que as casas legislativas dos estados brasileiros não apresentam, de modo geral, semelhança com as características da sociedade brasileira, uma vez que não espelham de forma fidedigna a sociedade como um microcosmo de quem a representa.

Palavras-chave: Estado e sociedade, sistema eleitoral, demografia, condição socioeconômica

[Artigo recebido em 20 de maio de 2015. Aprovado em 2 de março de 2016.] 
Rasgos socioeconómicos de la población y de sus representantes elegidos en las asambleas legislativas brasileñas: análisis de convergencia entre perfiles

El trabajo investiga la existencia de relación de similitud entre las características generales de los representantes elegidos en las asambleas legislativas y el perfil demográfico y socioeconómico de la población en edad de votar en las grandes regiones y en los estados brasileños. El estudio comparó el perfil de los representantes elegidos con respecto a sus rasgos generales, como sexo, edad, nivel de estudios y la ocupación en el período de 19982010, en relación con las características generales de la población con respecto a edad, sexo, nivel educativo y nivel de ingresos. Se concluye que las asambleas legislativas de los estados brasileños no presentan, en general, semejanza con las características de la sociedad brasileña, ya que no reflejan una imagen fidedigna de la sociedad como un microcosmo de quien la representa.

Palabras clave: Estadoy sociedad, sistema electoral, demografía, condición socioeconómica

Socioeconomic characteristics of the population and of their elected representatives in Brazilian legislative assemblies: analysis of convergence between profiles

The paper investigates the similarity relation between the general characteristics of the elected representatives in legislative assemblies and the demographic and socioeconomic profile of the population of voting age in the major regions and in the Brazilian states. The study analyzes the profile of the elected representatives concerning their general characteristics, i.e., gender, age, education level and occupation in the period 1998-2010, compared to the general characteristics of the population with respect age, sex, educational level and income level. It concludes that the legislative assemblies of the Brazilian states have no resemblance to the characteristics of Brazilian society. These do not reflect a reliable picture of society as a microcosm.

Keywords: State and society, electoral system, demography, socioeconomic conditions 


\section{Introdução}

O trabalho investiga a existência, empírica, de possível relação de similaridade no padrão e nos diferenciais dos perfis dos eleitos nas assembleias legislativas observados em pesquisas desenvolvidas para as grandes regiões e estados brasileiros (FUNDAÇÃo JoÃo PINHEIRO, 2013a; FundAÇÃo JoÃo PINHEIRO, 2013b; FundAÇÃo JoÃo PINHEIRO, 2014) com a diversidade demográfica e socioeconômica da sua população. Dentro de uma linha teórica que insere o processo eleitoral na temática da representação, o presente artigo se vale dos estudos de Urbinati (2006) e de Pitkin (1985) na busca de se identificar uma possível relação entre a teoria descritiva por semelhança na configuração de um suposto microcosmo da sociedade brasileira na composição das assembleias legislativas dos estados da Federação.

Considerando-se que os representantes das assembleias estaduais e distrital são eleitos pelo voto popular e que a distribuição desse grupo populacional também apresenta características sociais e econômicas distintas em todo o território nacional, indaga-se se diferenças constatadas no perfil dos eleitos, regionalmente, refletem da mesma forma as mudanças no perfil da população regional.

O presente estudo analisa comparativamente o perfil dos representantes eleitos no que se refere às suas características gerais - quais sejam: sexo, idade, nível de escolaridade e ocupação nos anos de 2002 e 2010 -, em relação às características gerais da população acerca das variáveis: sexo, idade, nível educacional e nível de renda.

Acredita-se que a construção de estudo relacional entre o perfil dos eleitos e o perfil da população poderá contribuir com as análises das características dos representados (população) que levem à melhor compreensão acerca das características dos representantes (membros eleitos do Poder Legislativo estadual).

\section{Processo eleitoral e representação política}

Kishlansky (1986, apud URBINATI, 2006), a partir de estudos acerca do nascimento do processo eleitoral na Inglaterra, relacionou "três fenômenos políticos: a adoção do método eleitoral para se designar os legisladores; a transformação dos eleitos, de delegados em representantes; e a emergência das alianças partidárias ou ideológicas entre os cidadãos." (KISHLANSKY, 1986 apud URBINATI, 2006, p. 195)

Mesmo consideradas aristocráticas, as eleições estimularam dois movimentos essenciais para a democratização. O primeiro distinguiu as relações entre Estado e sociedade, ou, nas palavras de Urbinati (2006), desencadeou as "relações simbióticas entre os delegados e suas comunidades para formas de unificação que eram totalmente simbólicas e construídas politicamente". O segundo dissociou os candidatos de suas posições ou classes sociais e destacou o papel das ideias 
na política, “ou, como preferiria dizer, o propósito idealizador do processo de representação" (URBINATI, 2006, p. 195).

Nesse sentido, a autora destaca que:

Como resultado, a representação não pode ser reduzida nem a um contrato (de delegação) firmado através das eleições, nem à nomeação de legisladores como substitutos do soberano ausente, porque sua natureza consiste em ser constantemente recriada e dinamicamente ligada à sociedade. Em suma, a história moderna sugere que a genealogia da democratização começou com o processo representativo (URBINATI, 2006, p. 195).

Segundo Urbinati (2006), quando se atenta para o funcionamento do governo representativo ao longo da história, pode-se dizer "que a representação tem sido interpretada alternativamente de acordo com três perspectivas: jurídica, institucional e política." As teorias jurídica e institucional se baseiam em um pressuposto formalista. A teoria jurídica trata a representação como um contrato que concede autorização para outrem realizar ações em nome da primeira. Nessa teoria, apresentam-se os conceitos de delegação (simbolizada por Rousseau) e alienação (identificada a partir dos argumentos de Hobbes) (URBINATI, 2006, p. 197).

O modelo jurídico configura a relação entre representado e representante conforme as linhas de uma lógica individualista e não-política, na medida em que supõe que os eleitores julgam as qualidades pessoais dos candidatos, ao invés de suas ideias políticas e projetos (URBINATI, 2006, p. 198).

Para Urbinati (2006), no que se refere à representação, tanto a teoria jurídica quanto a teoria institucional consideram que o Estado deve "transcender a sociedade de modo que se assegure o Estado de Direito, e que as pessoas devem encobrir suas identidades sociais e concretas para tornar os mandatários agentes imparciais de decisão" (URBINATI, 2006, p. 200).

E assim conclui, sobre a teoria jurídica e institucional:

Elas supõem que a identidade jurídica do eleitor/autorizador é vazia, abstrata e anônima, sua função consistindo em "nomear" políticos profissionais que tomem decisões às quais os eleitores se submetem voluntariamente. Assim, o que encontramos no sistema denominado representativo é que ele não é um sistema de representação do povo e da vontade da nação, mas um sistema de organização do povo e da vontade da nação (URBINATI, 2006, p. 200).

A teoria política apresenta nessa construção conceitual uma categoria nova, pois prevê a representação de forma dinâmica, criada pelos próprios atores, ou seja, eleitorado e seus representantes. Nesse contexto, Urbinati (2006) reflete: 
A representação política não elimina o centro de gravidade da sociedade democrática (o povo), ao mesmo tempo em que despreza a ideia de que os eleitores em vez dos cidadãos ocupem este centro, de que o ato de autorização seja mais importante do que o processo de autorização (URBINATI, 2006, p. 206).

Na busca de melhor compreensão sobre o pressuposto da representação, destaca-se o trabalho de Hanna Pitkin para uma construção conceitual capaz de propiciar melhor entendimento sobre o termo e sua utilização. Nesse contexto, Pitkin (1985) desenvolve em seus estudos diferentes linhas de raciocínio que caracterizam a representação. São elas a formalística, a simbólica, a substantiva (acting for) e a descritiva por semelhança.

A representação formalística, assim identificada por Pitkin (1985) a partir da definição de Hobbes, em sua obra $O$ Leviatã, concebe a ideia de representação mediante os arranjos estabelecidos pela autorização concedida para que um represente o todo. Nesse cenário, os representados concedem autoridade ao representante, que, dentro de seus limites, pode fazer o que lhe aprouver, não cabendo, aqui, a avaliação da representação boa ou ruim, uma vez que qualquer ato amparado dentro dos limites definidos é considerado ato representativo (PITKIN, 1985). A mesma autora conclui, pois, que o conceito de Hobbes sobre representação não se configura de forma plena, uma vez que, na situação de um soberano que não tem a obrigação de consultar seus súditos, não se guarda nenhuma semelhança com o que se pensa ser uma democracia representativa.

Nas palavras de Pitkin (1985):

¿Puede, entonces, la definición de Hobbes ser a la vez correcta e incorrecta? Tal vez pueda serlo en un sentido, si es una perspectiva verdadera aunque parcial de la representación; una perspectiva verdadera de una parte del significado del concepto, y sin embargo falsa si torna para definir todo el significado. Creo que Hobbes desarrolló una perspectiva demasiado estrecha de la representación abordándola sólo desde un ángulo, teniendo en cuenta únicamente una forma de representar (PITKIN, 1985, p. 39).

Outros teóricos estudados por Pitkin (1985) evidenciaram, dentro dos pressupostos da dita representação formalística, abordagens mais bem caracterizadoras de um modelo representativo, na visão da autora. Dentre eles, destacam-se Max Weber e Jellineka, Eric Voegelin, e os defensores da prestação de contas (accountability), além dos estudiosos da democracia representativa (PITKIN, 1985).

Já a representação simbólica retrata um emblema que representa o todo dentro das suas principais características, sugerindo qualidades internas em vez de semelhanças externas. Os símbolos não são necessariamente parecidos com o 
que representam, apenas sugestionam o representado a partir de um repositório de sentimentos e ações. Logo, a representação simbólica se fundamenta em questões de natureza psicológica e emocional não relacionadas a aspectos lógicos ou racionais (PITKIN, 1985).

La representación de un individuo en una sociedad es una condición que existe cuando las características y actos de una persona en una posición de poder en la sociedad están de acuerdo con los deseos, expresados y no expresados, del individuo (DE GRAZIA, 1951 apud PITKIN, 1985, p. 114).

A representação substantiva ou como um ato de 'agir por' (acting for) reflete as ações e responsabilidades do representante para com o representado e se centra na atividade de representar. Nos estudos de Pitkin (1985), não foram identificadas explicitamente abordagens desenvolvidas por teóricos que argumentassem sobre a representação mediante normas de comportamentos ou atitudes esperadas por parte dos representantes. Dentro dessa perspectiva, os estudos de Pitkin (1985) evidenciam abordagens relacionadas às obrigações dos representantes, sem se aprofundar nas suas ações e comportamentos e nas diferenças entre uma boa e uma má representação. Contudo, a autora afirma que, para a atividade substantiva, a literatura apresenta muitas ideias, por exemplo, ou o representante deve seguir as instruções que recebe do seu eleitorado, ou é livre para agir como quiser, ou mesmo age com discricionariedade em cada situação que se apresenta (PITKIN, 1985).

Por fim, o conceito de representação descritiva por semelhança apresentado por Pitkin (1985) busca responder à indagação sobre a formação de um corpo representativo de uma assembleia legislativa. Para a autora, o corpo representativo de uma casa legislativa deve responder às opiniões do povo, configurando-se como um retrato exato, em miniatura das pessoas em sua totalidade. Essa configuração deve se aproximar de maneira mais fiel a uma cópia da sociedade. A autora destaca outros estudos como o de Mill (1981), que defende a representação proporcional para garantir a neutralização da minoria no corpo representativo. Pitkin (1985) destaca que, na representação descritiva, o ato de representar não está relacionado à autoridade ou à prestação de contas, mas, sim, ao fato de que deve manter um retrato fiel da sociedade que representa. Para os autores dessa linha, um processo de seleção aleatória produziria um microcosmo do todo. Entretanto, Pitkin (1985) conclui que a mais perfeita réplica não irá duplicar todas as características da pintura original. Nesse sentido, devem ser diferenciados os representados dos representantes.

Hanna Pitkin cuida de se posicionar contrariamente à representação descritiva, que seria indesejável. Para a autora, essa noção é contestável porque: 
[...] assim como um mapa não é uma representação fiel da realidade, ou mesmo um espelho não reflete de forma pura a imagem diante dele, também um representante, por mais que se assemelhe àqueles que pensa representar, não pode ser considerado uma amostra do seu grupo (PITKIN, 1967 apud SACCHET, 2012, p. 411).

Além disso, a autora argumenta que a ênfase na composição do corpo legislativo desviaria a atenção do que é fundamental na representação, qual seja, o seu conteúdo. Afinal, o que importa é o que os representantes fazem, e não quem eles são. $O$ foco do argumento encontra-se no aspecto substantivo da representação. $A$ presença física de membros de grupos sociais distintos não seria considerada uma condição para que seus interesses sejam representados (SACCHET, 2012).

Detendo-se ao objeto de estudo do presente trabalho, destaca-se a noção de "representação descritiva" que, segundo Piktin (1985), conceberia o Parlamento como uma espécie de mapa, de microcosmo, no qual se veria imagem perfeita, espelho, embora em tamanho reduzido, da sociedade. Nesse caso, "haveria uma correspondência estreita entre as características do representante e as do representado" (SACCHET, 2012, p. 411).

Mesmo assim, a despeito das críticas acima sumarizadas, é comum observar que o debate acerca da representação especial de grupos - sobretudo, pela definição de cotas de inclusão - em muito se baseia nas premissas da representação descritiva. Vislumbra-se, nesse caso, a criação de mecanismos institucionais para que a proporção dos membros de dado grupo no Legislativo se aproxime do seu número na população (MANSBRIDGE, 1999 apud SACCHET, 2012).

Se de um lado o conceito acerca da representação ainda demonstra um campo de estudos e reflexões de alta complexidade, de outro, ao se buscar relação entre as características dos representantes e dos representados, evidenciam-se outras perspectivas que ainda merecem aprofundamento.

Dentro dos pressupostos da democracia participativa, nem sempre é possível a atuação direta de todos os cidadãos, o que reforça o debate sobre a qualidade da representação política no âmbito legislativo, na busca por um equilíbrio entre os interesses representados. Essa configuração idealizada evita o particularismo, de tal modo que o representante de um determinado segmento é capaz de defender os interesses que representa, sem deixar de reconhecer as necessidades e demandas de outros segmentos.

Nesse contexto, então, como se caracterizar o processo eleitoral e sua contribuição para a representação dos interesses dos cidadãos, dada a multiplicidade de variáveis envolvidas? Várias são as teorias que buscam melhor compreensão 
sobre a representação, aqui destacadas nos estudos de Pitkin (1985) e de Urbinati (2006). Não tendo a pretensão de esgotar a discussão sobre o tema, outros estudos discutem o comportamento eleitoral e apresentam algumas perspectivas teóricas que podem trazer outro olhar sobre a questão que, apesar de não retratar o foco principal do presente artigo, evidencia a amplitude e a complexidade do tema.

Dentre as principais teorias para explicar o comportamento eleitoral, destacam-se: a perspectiva sociológica, a psicológica e a teoria da escolha racional (Figueiredo, 1991; CAStro, 1994). Segundo Radmann (2001), no caso brasileiro, as perspectivas sociológicas e psicológicas mostraram-se mais relevantes na análise do comportamento eleitoral.

Na perspectiva sociológica, o ambiente social direciona o eleitor na escolha do seu voto. Vários estudos foram desenvolvidos partindo-se dessa premissa, procurando estabelecer uma relação entre a situação socioeconômica dos indivíduos e a opção partidária (SOARES, 1973; REIS, 1978). O eleitor seria influenciado por fatores históricos, estruturais e culturais globais, que determinariam as características sociais, econômicas e políticas de uma sociedade (CASTRO, 1994, p. 29), ou seja, os eleitores em situação social semelhante adotariam condutas político-eleitorais compatíveis com seu contexto.

Autores como Castro (1994), Almeida (1998), Silveira (1998), Magalhães (1998), e Baquero (2000) concluem que o voto dos eleitores de baixa sofisticação política direciona-se à pessoa do candidato e que essa escolha está diretamente associada à imagem do candidato. O eleitorado brasileiro, numa perspectiva geral, tem alto nível de desinformação e baixo grau de consistência ideológica, de apatia e ceticismo com relação às eleições. Mais importante do que a identificação partidária seria o personalismo político (BAQUERO, 1984, 1985, 1996, 1997; CASTRO, 1994; SILVEIRA, 1998; AlmeidA, 1998; MAGAlHÃES, 1998).

Por outro lado, na perspectiva psicológica, a unidade de análise é o indivíduo. Suas motivações e escolhas dão-se no nível psicológico, onde o seu comportamento eleitoral se desenvolve independentemente do contexto social, na estrutura de personalidade dos indivíduos, nos seus valores e crenças.

A perspectiva psicológica incorpora, nas análises do voto, fatores considerados intervenientes entre a situação socioeconômica do eleitor e o seu comportamento, com questões ligadas às percepções, às atitudes, às crenças, às opiniões e também às expectativas do eleitor (BAqUero, 1985; LAVAREDA, 1991; BAQUERO; Prá, 1995; REIS, 1978, 1988; CASTRO, 1994).

Segundo Carreirão (2004), pode-se observar que os eleitores não são indiferentes às características pessoais dos candidatos, como carisma, personalidade, qualificação pessoal e profissional. 
Radmann (2001) destaca que, na "abordagem psicológica, a identificação partidária e a participação política estão vinculadas diretamente às percepções e motivações dos indivíduos em relação à política e aos partidos" - que seriam determinados pela posição do indivíduo na estrutura da sociedade (RADMANN, 2001, p. 14). Indivíduos com a mesma formação social e atitudes semelhantes tendem a ter comportamentos sociais também semelhantes.

Em contrapartida, a teoria da escolha racional formula a concepção de homem político a partir da noção do homem econômico, na qual os eleitores desempenham seu papel social racionalmente, avaliando, entre os diversos partidos ou candidatos, aquele que poderá proporcionar maior benefício - racionalidade construída analisando custos e benefícios, tal qual um consumidor na esfera do mercado (RADMANN, 2001).

Em linhas semelhantes, outros autores aqui destacados contribuem em evidenciar aspectos do comportamento eleitoral. Oliveira (2010) elenca uma lista de motivações que podem determinar as escolhas dos eleitores, ou seja, ideologia, guia eleitoral ou estratégia de campanha, características do candidato, administração bem avaliada, e situação econômica do país ou do eleitor.

Nicolau (2006), ao refletir acerca do quadro geral do funcionamento do sistema eleitoral brasileiro de lista aberta, vigente para as eleições proporcionais do Poder Legislativo no Brasil, exceto para o Senado Federal, conclui que, nos estudos sobre as motivações que levam às escolhas dos eleitores, um dos principais temas é a influência dos atributos do candidato na decisão do eleitor, ou seja, o voto personalizado. No caso brasileiro, o voto popular está submetido ao sistema proporcional de lista aberta, em que o número de votos necessários para se eleger um candidato está condicionado ao quociente entre o número de votos válidos e o número de cadeiras ou vagas estabelecidas para cada assembleia legislativa. O eleitor pode votar nominalmente em um candidato ou em um partido, e ganham aqueles que alcançam o quociente eleitoral, ou seja, o número de votos mínimo necessário para se eleger um deputado, podendo haver transferência de votos para que se elejam os mais votados do partido ou coligação. Nessa premissa, apesar de o sistema proporcional de votação brasileira considerar que a representatividade da população deve se dar de acordo com a ideologia dos partidos ou coligações, podendo-se escolher preferencialmente um candidato, constata-se, pelo trabalho de Nicolau (2006), que o foco no candidato prevalece em relação ao partido ou a uma ideologia.

Nesse sentido, Nicolau (2006) cita Cain, Farejohn e Fiorina (1987) ao destacar que: 
O voto personalizado refere-se à porção do apoio eleitoral de um candidato que se origina em suas qualidades pessoais, qualificações, atividades e desempenho. A parte do voto que não é personalizada inclui apoio a um candidato baseado na sua filiação partidária, determinadas características do eleitor como classe, religião e etnia, reações às condições nacionais, tais como o estado da economia, e avaliação centrada no desempenho do partido que está no governo. (CAIN; FAREJOHN; FIORINA, 1987 apud NiCOLAU, 2006, p. 701. Tradução nossa)

Nicolau (2006) reflete, pois, que:

Não é possível interpretar o voto em candidatos como expressão pura e simples do voto personalizado porque muitos eleitores com vínculos mais permanentes com os partidos preferem, muitas vezes, votar em um nome específico da lista. Por outro lado, também não é possível dizer que o voto de legenda seja expressão exclusiva de identificação partidária de longo prazo (voto partidário), pois ele muitas vezes reflete escolhas de curto prazo motivadas pela campanha eleitoral (NICOLAU, 2006, p. 703-704).

Enfim, Nicolau (2006) apresenta os resultados de uma pesquisa desenvolvida pelo luperj em 2002, junto aos eleitores, na escolha de deputados federais. Ao ser questionado sobre o fator mais importante na escolha de seu candidato, $92 \%$ dos eleitores respondentes informaram que o candidato foi o fator mais importante, enquanto que somente $4 \%$ dos respondentes afirmaram ser o partido. Os demais eleitores respondentes informaram que tanto o candidato quanto o partido eram importantes para a escolha do eleitor.

Muitas pesquisas sobre o comportamento eleitoral brasileiro ostentam que os eleitores não acreditam nos partidos e não se interessam por política. Caracterizamse pela vulnerabilidade e volatilidade eleitoral. Mais ainda, inferem que a grande maioria dos eleitores, com baixo grau de informação, escolhe o seu voto em função da imagem e de atributos pessoais dos candidatos (BAQUERO; PrÁ, 1995; BAQUERO, 1984, 1985, 1996, 1997, 2000; CASTRO, 1994; GoldMANN; SANT'ANA, 1996; ALMEIDA, 1998; MAGALHÃES, 1998; SILVEIRA, 1998).

Contudo, reforça-se o desejo de se identificar indícios que permitam evidenciar aspectos de interseção, similaridade ou correspondência entre as características da população e os padrões de configuração do perfil dos deputados estaduais eleitos. Na tentativa de se estabelecer relação entre as teorias de representação, as características e peculiaridades do sistema eleitoral brasileiro e o comportamento do eleitor, detalha-se, a seguir, a metodologia que conduziu a presente pesquisa. 


\section{Metodologia}

O estudo desenvolvido se fundamentou em pesquisa bibliográfica, documental e de campo. De natureza descritiva, o presente trabalho configura-se como quantitativo, estruturado a partir de análise estatística de dados. Com o objetivo de conhecer e analisar comparativamente o perfil dos representantes eleitos nas assembleias legislativas brasileiras, foram utilizadas as informações disponibilizadas pelo Tribunal Superior Eleitoral (TSE) relativamente às eleições realizadas nos anos de 1998, 2002, 2006 e 2010¹. O repositório de dados eleitorais disponibilizados por meio da ferramenta "Consulta de Candidaturas" permitiu selecionar e analisar as variáveis de interesse específico do presente estudo, quais sejam: sexo, idade, escolaridade e ocupação².

Para a análise das características demográficas e socioeconômicas da população, empregou-se como fonte básica as informações dos censos demográficos de 2000 e 2010, no nível dos estados brasileiros, disponibilizados pelo IBGE. Optou-se pela não utilização dos dados do eleitorado fornecidos pelo Tribunal Superior Eleitoral, pelo fato de serem essas informações declaradas no momento do registro eleitoral, o que sugere que essas poderiam estar desatualizadas para parcela significativa da população.

Para construção do perfil demográfico da população, foram empregados dois indicadores: a proporção da população de 16 anos ou mais do sexo feminino e a idade média da população de 16 anos ou mais. Quanto ao nível socioeconômico da população, foram utilizados três indicadores. O primeiro, referente ao nível de escolaridade, considerou a proporção da população de 15 anos ou mais com mais de oito anos de estudos, para o ano de 2000, e a proporção da população de 15 anos ou mais com ensino superior completo para o ano de $2010^{3}$. Os dois indicadores restantes buscam retratar as condições econômicas da população em termos de rendimentos: a renda média domiciliar per capita ${ }^{4}$ e a proporção da população com baixa renda ${ }^{5}$.

\footnotetext{
${ }^{1}$ Disponível em <http://www.tse.jus.br/eleicoes/repositorio-de-dados-eleitorais>.

${ }^{2}$ Ressalta-se que serão analisadas as informações dos deputados estaduais eleitos pelo voto popular. A análise não leva em consideração aqueles eleitos por meio do voto recebido pelas legendas partidárias às quais são filiados.

${ }^{3}$ Os quesitos do Censo Demográfico de 2010 não permitem a construção da variável anos de estudos como no Censo Demográfico de 2000. Tal fato não inviabiliza a utilização de duas variáveis construídas de forma distinta, uma vez que as diferenças relativas entre os estados é que serão tomadas como ponto de comparação.

${ }^{4}$ Média das rendas domiciliares per capita das pessoas residentes em determinado espaço geográfico, no ano considerado.

${ }^{5}$ A definição de baixa renda seria a proporção da população com renda menor que $1 / 2$ salário mínimo. 0 salário mínimo do último ano para o qual a série está sendo calculada torna-se a referência para toda a série.
} 
Dado que o objetivo do estudo é associar as características demográficas e socioeconômicas da população (em idade de votar) com o perfil dos deputados estaduais eleitos ${ }^{6}$, no ano de 2000 , o perfil populacional será analisado contrapondose ao perfil dos deputados eleitos na eleição de 2002; e, no ano de 2010, o perfil populacional será associado ao perfil dos deputados eleitos na eleição de 2010.

Para a análise da relação entre as variáveis demográficas e socioeconômicas da população e o perfil dos eleitos, será empregado o coeficiente de correlação de Pearson, que mede o grau da correlação entre duas variáveis de escala métrica. Esse coeficiente assume valores entre -1 e 1, sendo que, no primeiro caso, significa perfeita correlação negativa entre as duas variáveis, ou seja, à medida que uma variável aumenta seu valor, a outra diminui. Por outro lado, o coeficiente de correlação será igual a um quando houver uma correlação perfeita positiva entre as duas variáveis.

\section{Análise do perfil dos eleitos nas assembleias legislativas brasileiras em relação ao perfil populacional}

A partir do cruzamento das informações levantadas, a análise estratificou o perfil dos eleitos nas assembleias legislativas dos estados brasileiros no período de 1998 a 2010 e buscou identificar relação com o perfil da população brasileira no mesmo período. A análise foi agrupada em características demográficas e socioeconômicas. A seguir, são apresentados os resultados da análise desenvolvida.

\section{Características demográficas}

As características demográficas aqui representadas incluem os quesitos sexo e idade, refletindo a evolução do perfil dos eleitos nas assembleias legislativas e do perfil da população no período 1998 a 2010.

\section{Sexo}

No campo político, as mulheres continuam sub-representadas na composição das assembleias. Tal constatação pode ter suas raízes na histórica desigualdade no campo social e econômico no Brasil em termos de análise de gênero. Importante destacar que, a despeito do sistema de cotas e do fato de a composição do eleitorado brasileiro ter se revertido no hiato de gênero, passando as mulheres a representarem a maioria dos votantes em todas as faixas etárias, tal constatação ainda se faz presente.

\footnotetext{
${ }^{6}$ Não serão considerados na análise de correlação os deputados eleitos no Distrito Federal, embora na apresentação e análise do perfil dos eleitos os resultados sejam apresentados.
} 
De forma generalizada, evidencia-se a predominância de deputados eleitos do sexo masculino no Brasil (Tabela 1). Em 1998, apenas 10,1\% dos eleitos no total do Brasil eram mulheres, passando 13,0\% em 2010, não se verificando, entretanto, padrão de crescimento ao longo das quatro últimas eleições.

Tabela 1 - Brasil e grandes regiões: percentual de deputados estaduais e distritais eleitos segundo sexo, 1998, 2020, 2006 e 2010

\begin{tabular}{l|rr|rr|rrr|r}
\hline & \multicolumn{2}{|c|}{1998} & \multicolumn{2}{c|}{2002} & \multicolumn{2}{c|}{2006} & \multicolumn{2}{c}{2010} \\
\cline { 2 - 9 } Grandes regiões & Feminino & Masculino & Feminino & Masculino & Feminino & Masculino & Feminino & Masculino \\
\hline Norte & 9,49 & 90,51 & 12,67 & 87,33 & 14,67 & 85,33 & 16,23 & 83,77 \\
Nordeste & 13,77 & 86,23 & 15,46 & 84,54 & 12,87 & 87,13 & 16,61 & 83,39 \\
Sudeste & 9,09 & 90,91 & 14,52 & 85,48 & 11,93 & 88,07 & 10,00 & 90,00 \\
Sul & 4,38 & 95,62 & 6,02 & 93,98 & 6,77 & 93,23 & 11,94 & 88,06 \\
Centro Oeste & 10,31 & 89,69 & 14,89 & 85,11 & 9,28 & 90,72 & 5,38 & 94,62 \\
& & & & & & & & \\
Brasil & 10,11 & 89,89 & 13,35 & 86,65 & 11,66 & 88,34 & 13,02 & 86,98 \\
\hline
\end{tabular}

Fonte: Fundação João Pinheiro (2013b, p. 13).

Analisando os estados brasileiros, contata-se o mesmo padrão observado para o Brasil como um todo, entretanto, com diferenciais ainda mais significativos. Regionalmente, observa-se elevada participação feminina no Norte, comparativamente às demais regiões, revelando internamente grande diversidade. Na eleição de 2010, chama atenção o volume de deputadas eleitas no Amapá: de 25,0\% (segundo maior percentual observado em termos dos estados brasileiros). Além disso, Tocantins, Pará, Acre e Rondônia apontavam participação feminina acima da média nacional (Gráfico 1).

Mesmo se destacando dentre as grandes regiões brasileiras pela maior participação feminina, o Nordeste apresenta comportamento significativamente díspar (FUNDAÇÃo JoÃo PINHEIRO, 2014). Destaca-se, na última eleição, o Estado do Piauí, que elegeu $25,9 \%$ de mulheres para sua assembleia - maior percentual observado entre todos os estados brasileiros e Distrito Federal. Destacam-se, ainda, Sergipe (23,8\%, terceiro maior percentual), Bahia $(19,4 \%)$, Maranhão $(18,9 \%)$, Paraíba $(18,8 \%)$ e Ceará $(15,4 \%)$, todos com participação feminina acima da média brasileira. 
Gráfico 1 - Brasil e Unidades da Federação: percentual de deputados estaduais e distritais eleitos do sexo feminino, 2010

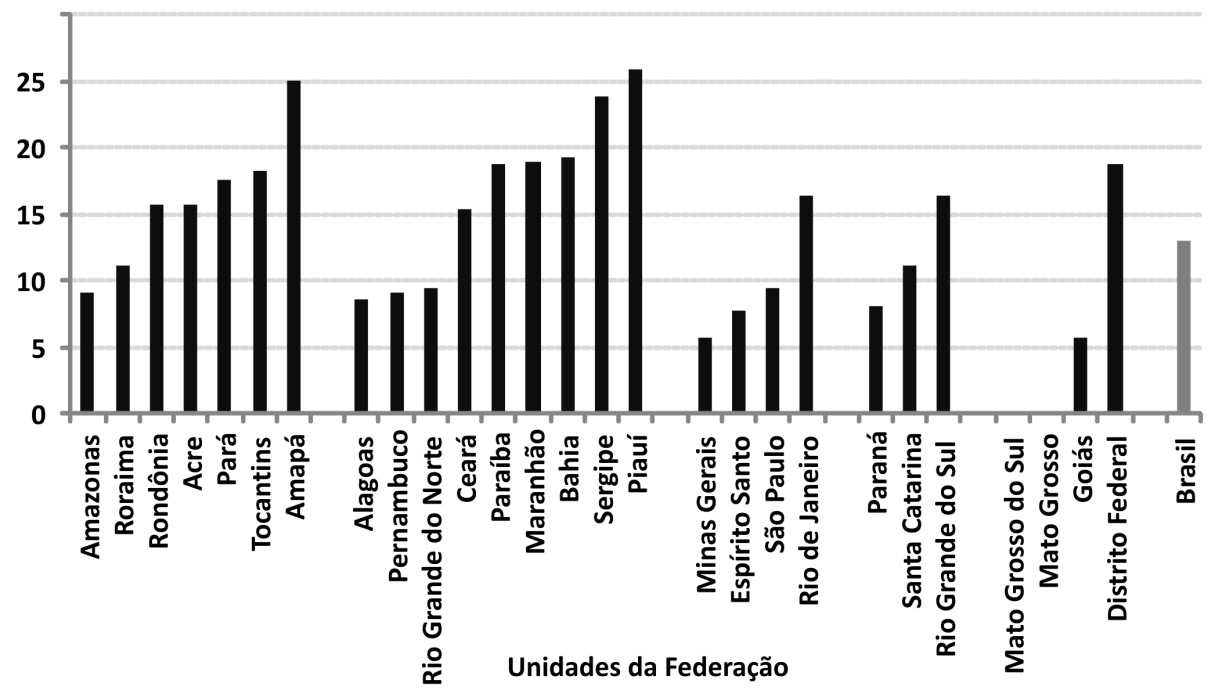

Fonte: Elaboração dos autores a partir de Fundação João Pinheiro (2014, p. 21).

Em termos de volume na representação segundo sexo, tem-se, em seguida, as Regiões Sul e Sudeste, onde a presença feminina é também pouco expressiva (FundaçÃo JoÃo PInheIro, 2014). Apenas os Estados do Rio Grande do Sul e Rio de Janeiro, ambos com pouco mais de $16,0 \%$ de mulheres nas assembleias estaduais nas eleições de 2010 , superam a média nacional.

Um quadro acentuado de desigualdade pode ser observado para os estados do Centro-Oeste. Enquanto o Distrito Federal contabiliza 18,8\% de mulheres eleitas, nos Estados de Mato Grosso do Sul e Mato Grosso, nenhuma representante feminina foi eleita, revelando disparidades importantes.

Analisando-se a composição das assembleias nas últimas quatro eleições segundo as regiões, fica evidente, no Norte e Sul, crescimento sistemático da participação das mulheres (FUNDAÇÃo JOÃo PINHEIRO, 2013b). O estudo chama atenção para o Sul, com o maior crescimento entre 1998 e 2010. Nesse período, praticamente triplicou seu percentual. Não se observa padrão similar nas demais regiões, com variações positivas e negativas ao longo do período analisado.

A composição das assembleias relativamente à composição segundo sexo poderia ser explicada pelas características populacionais nos diferentes estados? Em termos de representatividade, os estados com os maiores quantitativos populacionais de mulheres tenderiam a apresentar bancadas com maior percentual de mulheres? Fatores econômicos e sociais poderiam explicar maior ou menor eleição de mulheres? 
Os maiores ou menores percentuais de mulheres eleitas não podem ser atribuídos aos diferenciais populacionais quanto à composição segundo sexo (Tabela 2). Ou seja, os diferenciais observados em termos da efetiva participação feminina nas assembleias nos anos de 2002 e 2010 não encontram correlação significativa com a proporção de mulheres na população brasileira. Dessa forma, não é possível constatar a formação de um corpo representativo no que se refere ao sexo.

Tabela 2 - Correlação de Pearson entre a proporção de deputadas eleitas e os indicadores selecionados, 2002 e 2010

\begin{tabular}{|c|c|c|c|}
\hline \multirow[t]{2}{*}{ Especificação } & & \multicolumn{2}{|c|}{ Proporção Deputadas eleitas } \\
\hline & & 2002 & 2010 \\
\hline \multirow[t]{2}{*}{ Proporção de mulheres } & Correlação & 0,3287 & 0,1564 \\
\hline & Significância & 0,1011 & 0,4456 \\
\hline \multirow[t]{2}{*}{ Escolaridade } & Correlação & $-0,0433$ & $-0,3940 *$ \\
\hline & Significância & 0,8335 & 0,0464 \\
\hline \multirow[t]{2}{*}{ Idade média } & Correlação & 0,0095 & $-0,2035$ \\
\hline & Significância & 0,9632 & 0,3187 \\
\hline \multirow[t]{2}{*}{ Baixa renda } & Correlação & 0,2350 & $0,4989 * *$ \\
\hline & Significância & 0,2479 & 0,0095 \\
\hline \multirow[t]{2}{*}{ Renda média per capita } & Correlação & $-0,2001$ & $-0,4313 *$ \\
\hline & Significância & 0,3271 & 0,0278 \\
\hline
\end{tabular}

Fonte: Elaboração dos autores.

** Significância de 0,01

* Significância de 0,05

Os diferenciais, segundo sexo, poderiam ser explicados por outras características populacionais. Analisando as variáveis socioeconômicas selecionadas, observa-se que a renda média domiciliar per capita e a escolaridade da população nos estados teriam relação negativa com a proporção de deputadas eleitas, ou seja, estados com as menores rendas e escolaridade mais baixa seriam aqueles com as maiores participações femininas (no nível de 0,05 de significância), sendo tal relação estatisticamente significativa apenas no perfil dos eleitos em 2010. À medida que aumenta a renda e a escolaridade da população, diminui a participação das mulheres na composição das assembleias estaduais. 
Destaca-se ainda a correlação positiva desse percentual com o indicador de pobreza, com maior significância. As maiores proporções de deputadas eleitas encontram-se nos estados com as maiores proporções de população de baixa renda, sendo que à medida que essa proporção cai, diminui a participação das mulheres eleitas (no nível de 0,01 de significância).

\section{Idade}

De forma generalizada, evidencia-se o envelhecimento da estrutura etária dos deputados. A faixa etária com maior participação das bancadas de deputados nas eleições de 1998 a 2010 foi a de 40 a 49 anos, seguida pela faixa etária de 50-59 e 30-39 anos. Apesar da faixa etária de 40 a 49 anos apresentar a maior participação na última eleição, essa vem decrescendo ao longo das últimas quatro eleições, passando de 42\% para 33\% no Brasil entre 1998 e 2010 (FUnDAÇÃo JoÃo PINHEIRO, 2013a; FundAÇÃo JoÃo PINHEIRO, 2013b), resultando na elevação da idade média dos deputados eleitos.

No Brasil, em 1998, a idade média estava em torno dos 45 anos, crescendo paulatinamente nas eleições seguintes, chegando em 2010 a uma idade média próxima dos 48 anos (Tabela 3). O fenômeno da transição demográfica, alterando sobremaneira a estrutura etária da população brasileira, poderia explicar em parte tal constatação. A queda dos níveis de fecundidade das mulheres ao longo das últimas décadas desencadeou acentuado processo de envelhecimento populacional (FunDAÇÃo JoÃo PINHEIRO, 2013b).

De forma geral, aumenta a idade média dos deputados estaduais e distritais eleitos no período analisado para o total do País, assim como nas grandes regiões. Ao longo das quatro últimas eleições, a idade média dos deputados eleitos no Sudeste e Sul foi maior do que a média brasileira, e o maior crescimento foi observado no Norte (Tabela 3).

Tabela 3 - Brasil e grandes regiões: idade média dos deputados estaduais e distritais eleitos, 1998, 2020, 2006 e 2010

\begin{tabular}{lrr|r|r}
\hline \multicolumn{1}{c}{ Grandes regiões } & \multicolumn{1}{c|}{1998} & \multicolumn{1}{c|}{2002} & \multicolumn{1}{c}{2006} & \multicolumn{1}{c}{2010} \\
\hline Norte & 41,82 & 42,93 & 44,69 & 46,49 \\
Nordeste & 44,70 & 44,91 & 46,70 & 47,25 \\
Sudeste & 46,71 & 46,26 & 47,44 & 48,77 \\
Sul & 45,51 & 46,80 & 48,32 & 49,10 \\
Centro Oeste & 45,62 & 44,87 & 46,02 & 47,87 \\
& & & & \\
Brasil & 44,97 & 45,22 & 46,77 & 47,85 \\
\hline
\end{tabular}

Fonte: Fundação João Pinheiro (2013b, p. 21). 
A mesma constatação pode ser feita quando analisada a composição segundo os estados brasileiros. O estudo desenvolvido por Fundação João Pinheiro (2014) aponta que há aumento da idade média dos deputados eleitos entre os pleitos de 1998 e 2010, com exceção apenas de Pernambuco e Goiás. Vale destacar que os diferenciais em termos dos estados foram mais significativos comparativamente às médias regionais.

Gráfico 2 - Brasil e Unidades da Federação: idade média dos deputados estaduais e distritais eleitos, 2010

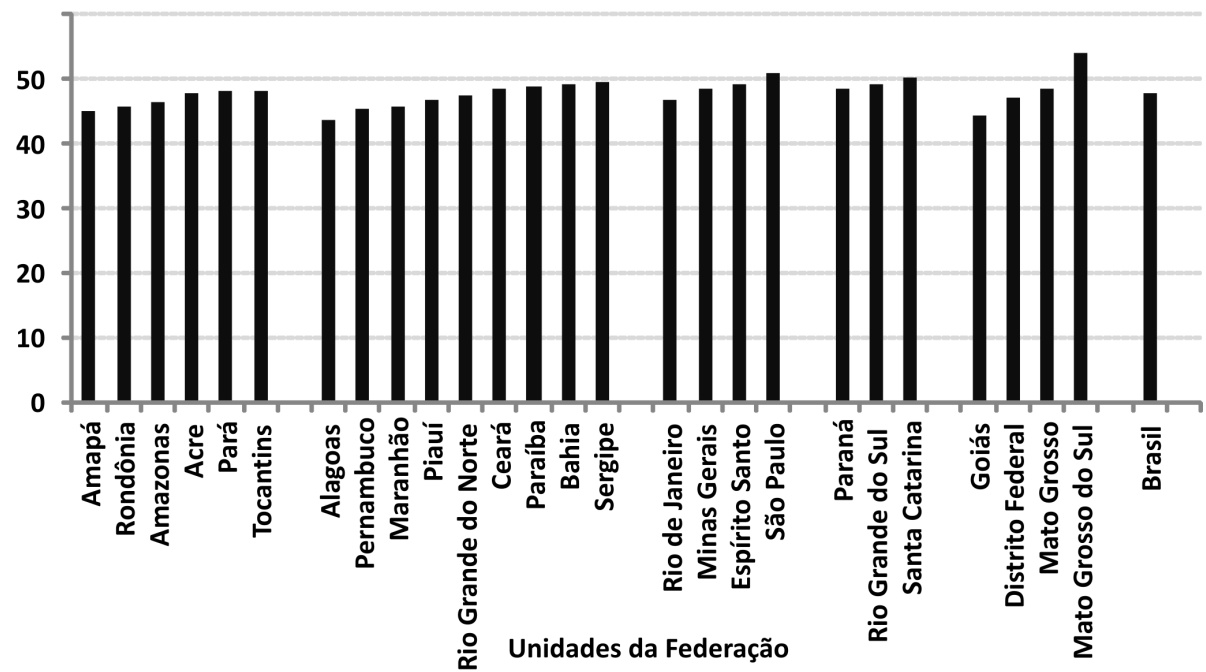

Fonte: Elaboração dos autores a partir de Fundação João Pinheiro (2014, p. 51).

Via de regra, as maiores idades médias foram observadas no Sul e Sudeste, ao passo que as menores idades médias localizam-se no Nordeste e Norte. Dada a diversidade dos estados, não foi possível constatar um padrão específico para cada uma das grandes regiões. É possível, por exemplo, observar estados com idades médias dos seus deputados eleitos acima ou abaixo da média brasileira (Gráfico 2).

Analisando-se os coeficientes de correlação dos indicadores demográficos e socioeconômicos selecionados e a idade média dos deputados eleitos segundo os estados brasileiros, verificam-se relações estatisticamente significativas, principalmente no ano de 2010.

Estritamente no que se refere ao conceito da representação por similaridade segundo "composição etária", os resultados apontam correlação positiva e significativa (no nível de 0,05 de significância) entre a idade média dos deputados eleitos e a idade média da população, tanto em 2002 como em 2010. Ou seja, os estados que têm uma população mais velha têm também bancadas estaduais 
mais velhas. À medida que diminui a idade média da população, cai a idade média dos deputados eleitos, determinando, consequentemente, similaridade entre representantes e representados.

Tabela 4 - Correlação de Pearson entre a idade média dos deputados eleitos e os indicadores selecionados, 2002 e 2010

\begin{tabular}{|c|c|c|c|}
\hline \multirow[t]{2}{*}{ Especificação } & & \multicolumn{2}{|c|}{ Idade média } \\
\hline & & 2002 & 2010 \\
\hline \multirow[t]{2}{*}{ Proporção de mulheres } & Correlação & 0,2570 & 0,1003 \\
\hline & Significância & 0,2049 & 0,6260 \\
\hline \multirow[t]{2}{*}{ Escolaridade } & Correlação & 0,1584 & $0,4001 *$ \\
\hline & Significância & 0,4397 & 0,0428 \\
\hline \multirow[t]{2}{*}{ Idade média } & Correlação & $0,5519 *$ & $0,4445 *$ \\
\hline & Significância & 0,0035 & 0,0229 \\
\hline \multirow[t]{2}{*}{ Baixa renda } & Correlação & $-0,2776$ & $-0,4087 *$ \\
\hline & Significância & 0,1697 & 0,0382 \\
\hline \multirow[t]{2}{*}{ Renda média per capita } & Correlação & 0,3025 & $0,3889 *$ \\
\hline & Significância & 0,1331 & 0,0496 \\
\hline
\end{tabular}

Fonte: Elaboração dos autores.

** Significância de 0,01

* Significância de 0,05

Mais ainda, outras características socioeconômicas da população também contribuem para a consolidação do perfil dos deputados eleitos, sendo estatisticamente significativas apenas para 2010. Positivamente, tem-se a escolaridade e a renda média per capita. Ou seja, quanto maior a proporção da população com nível superior completo ou maior a idade média da população ou maior a renda média domiciliar per capita nos estados, maiores serão as idades médias dos eleitos. À medida que diminui a proporção da população mais escolarizada ou diminui a idade média ou a renda média domiciliar cai, a idade média das bancadas estaduais também reduz. Por outro lado, a maior proporção de população com baixa renda dos estados estaria negativamente correlacionada à idade média dos deputados nesses mesmos estados. Estados com maior proporção de população "pobre" têm deputados estaduais com idade média mais baixa (Tabela 4). 


\section{Características socioeconômicas}

As características socioeconômicas aqui representadas incluem os quesitos escolaridade e ocupação ${ }^{7}$, refletindo a evolução do perfil dos eleitos nas assembleias legislativas e do perfil da população no período 1998 a 2010.

\section{Escolaridade}

De forma geral, pode-se observar elevação no nível de escolaridade dos deputados estaduais e distritais eleitos. No ano de 1998, 63,4\% declararam possuir o nível superior completo, passando para 70,1\% no ano de 2010. Dessa forma, poder-se-ia apontar a preferência dos eleitores brasileiros por candidatos com curso superior, o que indicaria, portanto, que as pessoas com baixa escolaridade têm mínimas chances de chegar a deputado estadual ou distrital (FUNDAÇÃo JoÃo PINHEIRO, 2013b).

Tabela 5 - Brasil: percentual de deputados estaduais e distritais eleitos segundo escolaridade, 1998, 2002, 2006 e 2010

\begin{tabular}{c|c|c|c|c|c|c|c|c}
\hline & \multicolumn{7}{|c|}{ Nível de escolaridade } & \\
\cline { 2 - 8 } Ano & Lê e escreve & $\begin{array}{c}\text { 10 Grau } \\
\text { incompleto }\end{array}$ & $\begin{array}{c}\text { 10 Grau } \\
\text { completo }\end{array}$ & $\begin{array}{c}\text { 20 Grau } \\
\text { incompleto }\end{array}$ & $\begin{array}{c}\text { 20 Grau } \\
\text { completo }\end{array}$ & $\begin{array}{c}\text { Superior } \\
\text { incompleto }\end{array}$ & $\begin{array}{c}\text { Superior } \\
\text { completo }\end{array}$ & Total \\
\hline 1998 & 0,32 & 2,76 & 2,65 & 3,40 & 16,77 & 10,40 & 63,69 & 100,00 \\
2002 & 0,55 & 3,49 & 2,29 & 3,60 & 13,97 & 13,32 & 62,77 & 100,00 \\
2006 & 0,11 & 1,73 & 4,43 & 2,16 & 13,71 & 10,58 & 67,28 & 100,00 \\
2010 & 0,11 & 0,87 & 3,36 & 0,87 & 13,34 & 11,39 & 70,07 & 100,00 \\
\hline
\end{tabular}

Fonte: Fundação João Pinheiro (2013b, p. 27).

Apesar de persistirem os diferenciais regionais, observa-se aumento do percentual de deputados eleitos com escolaridade superior completo entre as eleições de 1998 e 2010, em todas as cinco grandes regiões brasileiras. O Norte destaca-se dentre as demais. No período analisado, o percentual de deputados com escolaridade superior passa de apenas 38,6\%, em 1998, para 64,3\%, em 2010 (Tabela 6).

\footnotetext{
7 Dadas as especificidades da análise da composição ocupacional dos eleitos (reeleitos ou não), o mesmo perfil não foi considerado para a população brasileira. As demais características demográficas e socioeconômicas permanecem na análise.
} 
Tabela 6 - Brasil e grandes regiões: percentual de deputados estaduais e distritais eleitos com superior completo, 1998, 2020, 2006 e 2010

\begin{tabular}{lr|r|r|r}
\hline \multicolumn{1}{c}{ Grandes regiões } & 1998 & 2002 & \multicolumn{1}{c|}{2006} & \multicolumn{1}{c}{2010} \\
\hline Norte & 38,61 & 48,00 & 50,67 & 64,29 \\
Nordeste & 68,20 & 68,09 & 73,60 & 71,10 \\
Sudeste & 70,75 & 66,13 & 72,43 & 73,33 \\
Sul & 64,96 & 54,14 & 63,91 & 69,40 \\
Centro Oeste & 64,95 & 63,83 & 64,95 & 68,82 \\
& & & & \\
Brasil & 63,16 & 61,83 & 67,28 & 70,07 \\
\hline
\end{tabular}

Fonte: Fundação João Pinheiro (2013b, p. 28).

Os resultados apontam, ao longo das últimas quatro eleições, comportamento diferenciado, com destaque para Sudeste e Nordeste, que, em todos os pleitos, foram aquelas com os melhores resultados, ou seja, os maiores percentuais de deputados eleitos com alto nível de escolaridade (FundAção JoÃo PINHEIRO, 2013b).

Com diferenciais bem menos importantes, mas acima da média nacional, destacam-se Sudeste e Nordeste na eleição de 2010 - 73,3\% e 71,1\% -, respectivamente. O Norte, apesar da evolução extremamente significativa, permanece com o menor percentual de deputados com nível superior de escolaridade declarado (64,3\%).

O mesmo comportamento foi observado analisando-se os resultados dos estados brasileiros. Verificou-se que, apesar de persistirem os diferenciais regionais, observa-se aumento do percentual de deputados eleitos com escolaridade "superior completo" entre as eleições de 1998 e 2010 em praticamente todos os estados, com exceção para Paraíba, Rio Grande do Norte, São Paulo, Rio Grande do Sul e Goiás, que tiveram percentuais reduzidos; e Rondônia e Minas Gerais, que praticamente não alteraram seu percentual (FundAÇÃo JoÃo PINHEIRO, 2014). Não é possível estabelecer padrão entre os estados brasileiros em termos regionais. Altos e baixos percentuais de deputados com nível de escolaridade superior são observados tanto nas regiões mais desenvolvidas do Brasil, quanto nas menos desenvolvidas (Gráfico 3). 
Gráfico 3 - Brasil e Unidades da Federação: proporção de deputados estaduais e distritais eleitos com nível superior completo, 2010

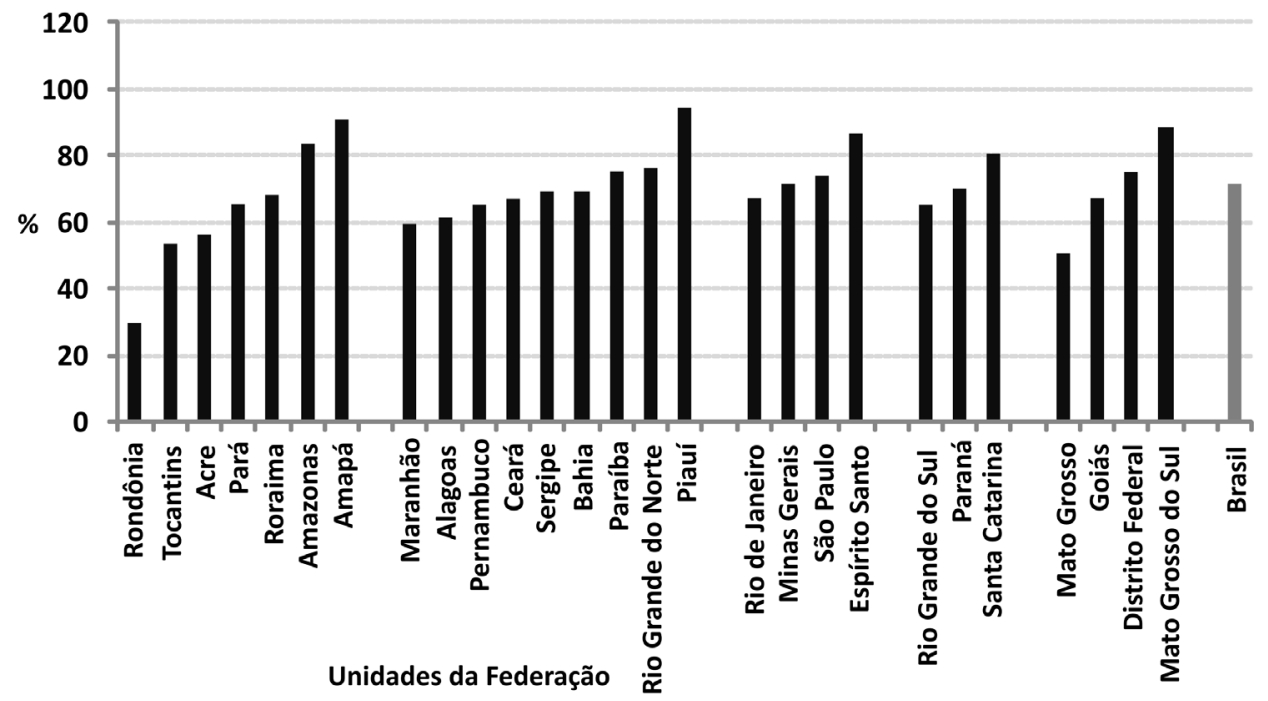

Fonte: Elaboração dos autores a partir de Fundação João Pinheiro (2014, p. 86).

Analisando uma possível relação entre nível de escolaridade dos deputados eleitos e da população brasileira, pode-se dizer que não existe similaridade nas assembleias legislativas na composição segundo nível educacional.

Incorporando as demais variáveis, tem-se que a diversidade regional em relação aos fatores demográficos e socioeconômicos da população brasileira, analisados conjuntamente com a diversidade em termos de escolaridade dos deputados eleitos, não apresenta um padrão associativo nos resultados da última eleição. Apenas em 2002 foi possível observar valores estatisticamente significativos (nível de significância de 0,01 ). Os resultados mostram que a proporção de deputados eleitos com nível superior completo de escolaridade está relacionada positivamente à idade média da população e à proporção de mulheres na população. Ou seja, estados com idade média maior tendem a eleger uma proporção maior de candidatos com nível superior completo. À medida que a idade média diminui, cai a proporção de deputados com nível superior de escolaridade. Na mesma direção, estados com maior proporção de mulheres na população teriam as maiores proporções de eleitos com maior escolaridade. À medida que a proporção de mulheres reduz, diminui a proporção de deputados com escolaridade superior (Tabela 7). 
Tabela 7 - Correlação de Pearson entre a escolaridade dos deputados eleitos e os indicadores selecionados, 2002 e 2010

\begin{tabular}{ll|c|r}
\hline \multirow{2}{*}{ Especificação } & & \multicolumn{2}{|c}{ Escolaridade } \\
\cline { 3 - 4 } & & 2002 & 2010 \\
\hline Proporção de mulheres & Correlação & $0,5540 * *$ & 0,3170 \\
& Significância & 0,0033 & 0,1145 \\
Escolaridade & Correlação & $-0,2347$ & 0,1579 \\
& Significância & 0,2484 & 0,4410 \\
Idade média & Correlação & $0,5602 * *$ & 0,1315 \\
& Significância & 0,0029 & 0,5219 \\
Baixa renda & Correlação & 0,1393 & 0,0026 \\
& Significância & 0,4973 & 0,9899 \\
Renda média per capita & Correlação & $-0,0640$ & 0,0423 \\
& Significância & 0,7561 & 0,8373 \\
\hline
\end{tabular}

Fonte: Elaboração dos autores.

** Significância de 0,01

* Significância de 0,05

\section{Ocupação}

Em relação à ocupação declarada pelos deputados, chama a atenção o aumento significativo, entre os deputados eleitos, daqueles que se declararam como pertencentes ao grupo dos membros superiores do poder público, dirigentes de organizações de interesse público e de empresas, gerentes. Constata-se que há tendência à profissionalização na carreira da representação legislativa, podendo significar maior ativismo ou mesmo o amadurecimento político da sociedade brasileira (FUNDAÇÃo JOÃO PINHEIRO, 2014).

Ao longo do período analisado, os "profissionais das ciências e das artes" apresentaram participação expressiva entre as ocupações declaradas pelos candidatos eleitos, entretanto, com clara tendência de redução (FuNDAÇÃo JoÃo PINHEIRO, 2013a).

O que chama atenção, no entanto, é que no período de 1998 a 2010, toma vulto a participação dos "membros superiores do poder público, dirigentes de organizações de interesse político e de empresas e gerentes" (praticamente dobra). Tal constatação é relevante, tanto pelo fato do significativo crescimento da 
participação do referido grupo ao longo das últimas quatro eleições quanto pela importância relativa observada no ano de 2010. Na última eleição, caracteriza-se por representar mais da metade dos eleitos $(56,5 \%)$. A possibilidade da reeleição cria a "carreira parlamentar".

Evidencia-se a tendência em reeleger candidatos já engajados na "vida política". Em 2010, praticamente todos os estados apresentavam percentuais superiores a 50\%, com exceção dos Estados da Paraíba, Pernambuco, Alagoas, Bahia, Espírito Santo, Mato Grosso do Sul e Goiás - destacando-se que esses tinham percentuais variando entre $38 \%$ e 48\%. Nos Estados do Amapá, Rondônia, Minas Gerais, Santa Catarina, Paraná e Mato Grosso, mais de dois terços dos representantes eleitos declaram-se da carreira "política" (Gráfico 4).

Gráfico 4 - Brasil e Unidades da Federação: proporção dos deputados estaduais e distritais reeleitos, 2010

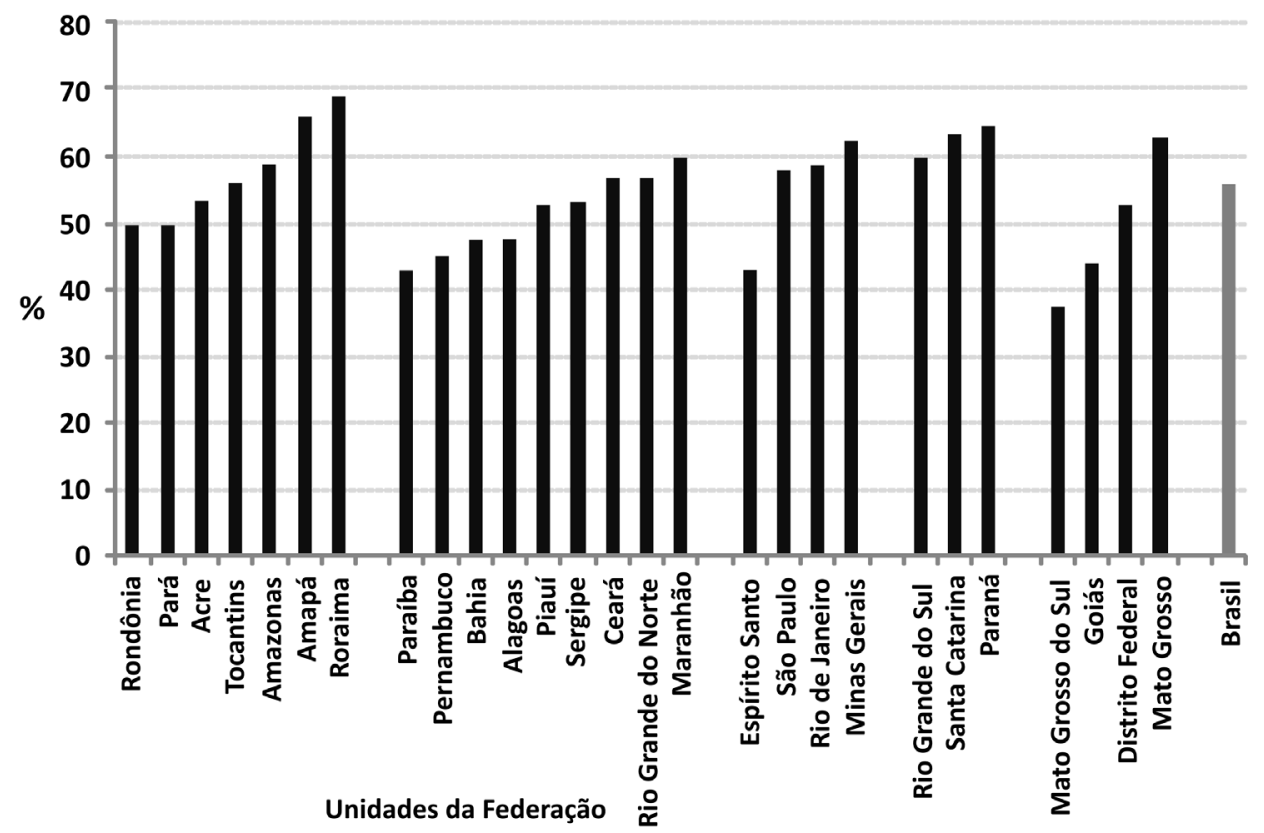

Fonte: Elaboração dos autores a partir de Fundação João Pinheiro (2014, p.90)

Considerando-se o percentual de deputados "reeleitos" como indicador de ocupação de peso na presente análise e buscando-se possível associação com as variáveis demográficas e socioeconômicas da população, somente no ano de 2002 foi possível constatar correlação significativa (nível de significância de 0,05). Apenas para a proporção de mulheres é que determina uma relação negativa com a 
proporção de deputados "reeleitos", ou seja, os estados com as menores proporções de mulheres seriam aqueles com os maiores percentuais de reeleição (Tabela 8).

Tabela 8 - Correlação de Pearson entre a ocupação dos deputados eleitos e os indicadores selecionados, 2002 e 2010

\begin{tabular}{ll|c|r}
\hline \multirow{2}{*}{ Especificação } & & \multicolumn{2}{|c}{ Ocupação } \\
\cline { 3 - 4 } & & 2002 & 2010 \\
\hline Proporção de mulheres & Correlação & $-0,4347 *$ & $-0,2349$ \\
& Significância & 0,0265 & 0,2481 \\
& & & \\
Escolaridade & Correlação & $-0,1078$ & 0,2043 \\
& Significância & 0,6002 & 0,3167 \\
Idade média & Correlação & & $-0,0280$ \\
& Significância & 0,3408 & 0,8919 \\
Baixa renda & Correlação & 0,0035 & $-0,2781$ \\
& Significância & 0,9866 & 0,1689 \\
Renda média per capita & Correlação & & 0,2558 \\
& Significância & 0,0518 & 0,2072 \\
\hline
\end{tabular}

Fonte: Elaboração dos autores.

** Significância de 0,01

* Significância de 0,05

\section{Síntese dos resultados da pesquisa}

Investigou-se, inicialmente, uma possível situação de similaridade entre os deputados eleitos e a população tomando-se as características analisadas. Outras possíveis variáveis explicativas foram exploradas com o propósito de analisar se os diferenciais identificados poderiam estar relacionados à diversidade demográfica e socioeconômica regional da população brasileira, mais especificamente aquela com idade para votar.

No que se refere à similaridade, apenas a idade média da população está positivamente correlacionada à idade média dos eleitos, ou seja, naqueles estados onde a idade média da sua população é maior, encontram-se também as assembleias compostas por deputados com idade média mais elevada. À medida que a idade média populacional diminuiu, diminui também a idade média dos candidatos eleitos. O mesmo não foi observado para as características sexo e nível de escolaridade. 
No que se refere às demais relações analisadas, pode-se constatar que na eleição de 2002 apenas a idade média da população e a proporção de mulheres estariam correlacionadas a certas características do perfil dos deputados estaduais e distritais eleitos.

A pesquisa evidenciou que o indicador "idade média da população" encontrase relacionado positivamente com a escolaridade dos eleitos, mensurada pela proporção de deputados com curso superior completo. Estados com as maiores idades médias têm suas bancadas formadas por deputados também de maior escolaridade. Além desse indicador, a proporção de mulheres na população também responderia positivamente pela escolaridade dos eleitos. Estados com maior composição feminina teriam bancadas formadas por elevada proporção de eleitos com nível superior completo.

A proporção de mulheres em relação à população de potenciais "eleitores" está associada ainda com a ocupação dos deputados eleitos, mensurada pela variável "proporção de deputados" que declararam ocupação na categoria "membros superiores e dirigentes do poder público", ou seja, da "carreira política" ou "reeleitos". Quanto maior a proporção de mulheres nos estados, menor será a proporção dos "reeleitos".

Na eleição de 2010, os resultados mudam significativamente. Inicialmente, podese dizer que a escolaridade e a ocupação dos deputados eleitos não se encontram correlacionados com nenhum dos indicadores populacionais selecionados. Apenas o percentual de mulheres eleitas e a idade média estariam associados a certas características populacionais, entretanto, de maneira distinta.

Estados com as mais elevadas proporções de mulheres eleitas seriam aqueles com a menor proporção da população com nível de escolaridade superior e com as maiores proporções de população de baixa renda. À medida que a escolaridade aumenta e a proporção de população carente diminui, a proporção de deputadas eleitas diminui.

Finalmente, no que se refere à idade média dos deputados eleitos, pode-se observar que quanto maior a proporção da população com nível superior completo, maior a idade média da população ou maior a renda média domiciliar per capita dos estados, maiores serão as idades médias dos eleitos nesses estados. Por outro lado, a maior proporção de população com baixa renda dos estados estaria negativamente correlacionada à idade média dos deputados nesses mesmos estados.

\section{Conclusão}

A despeito dos estudos e teorias apresentados, ainda persiste a dificuldade de explicar como a escolha do eleitorado nas eleições possibilita garantir a representatividade de interesses nas assembleias legislativas estaduais, haja vista a 
diversidade da sociedade brasileira. Ao investigar a existência empírica de possível relação de similaridade no padrão e nos diferenciais dos perfis dos eleitos nas assembleias legislativas observados em pesquisas desenvolvidas para as grandes regiões e estados brasileiros e a diversidade demográfica e socioeconômica da sua população, chega-se, pois, às seguintes reflexões:

- considerando-se os estudos de Urbinati (2006), que buscam estabelecer relação entre o processo eleitoral e a representação, bem como identificar tipos de representação oriundas das eleições, e considerando-se as tipologias identificadas por Pitkin (1985), especificamente a descritiva por semelhança, cuja caracterização retrata a representação como um microcosmo que espelha o todo de forma fiel, evidenciando a presença, mesmo que emblemática, de grupos representativos do todo, no caso, da sociedade nas casas legislativas;

- considerando-se que os representantes das casas legislativas dos estados brasileiros são eleitos pelo voto popular dentro do sistema proporcional de lista aberta, em que o número de votos necessário para se eleger um candidato está condicionado ao quociente entre o número de votos válidos e o número de cadeiras ou vagas estabelecido para cada assembleia legislativa, podendo haver transferência de votos para que se elejam os mais votados do partido ou coligação, uma vez que considera que a representatividade da população deve se dar de acordo com a ideologia dos partidos ou coligações, podendo se escolher preferencialmente um candidato;

- considerando-se que a despeito das distintas características e peculiaridades regionais brasileiras (culturais, sociais e econômicas), observa-se certa homogeneização em termos dos padrões demográfico e socioeconômico dos deputados estaduais e distritais eleitos nas últimas quatro eleições, ou seja, homens com idade em torno dos 50 anos com curso superior completo e ocupação declarada na categoria "membros superiores e dirigentes do Poder Executivo e Legislativo", o que denota que foram reeleitos, e que tais padrões podem ser observados tanto nas grandes regiões quanto nos estados brasileiros, entretanto, em patamares bastante distintos, principalmente nesse último nível geográfico;

- e, considerando-se as características do perfil da população brasileira segundo os indicadores proporção de mulheres, idade média, escolaridade e rendimento, além dos indicadores proporção de população com baixa renda e renda média domiciliar per capita, analisadas comparativamente aos padrões característicos do perfil dos deputados estaduais eleitos. 
Conclui-se que, dentro da linha teórica que insere o processo eleitoral na temática da representação e do comportamento eleitoral, o presente estudo, ao buscar uma possível correlação entre e a teoria descritiva por semelhança na composição das assembleias legislativas dos estados da Federação, investigada por possíveis evidências que pudessem retratar o perfil dos representados em relação ao perfil dos seus representantes, ou seja, na configuração de um suposto microcosmo da sociedade brasileira nas respectivas casas legislativas estaduais, constata-se a impossibilidade de se estabelecer tal relação. As disparidades nas correlações entre perfil dos eleitos e da população tornam claros os indicativos de que as casas legislativas dos estados brasileiros não apresentam, de modo geral, semelhança com as características da sociedade brasileira, dentro dos pressupostos da teoria descritiva por semelhança proposta por Pitkin (1985), uma vez que não espelham de forma fidedigna a sociedade como um microcosmo de quem a representa.

Tendo em vista tal constatação, é possível inferir em eventuais interpretações acerca das discrepâncias identificadas entre os perfis da população em relação aos de seus representantes nas casas legislativas estaduais. Entre elas, pode-se contemplar aspectos da cultura e dos valores da sociedade brasileira construídos ao longo da história, bem como o caráter elitista dos pleitos, e, por fim, a configuração do sistema proporcional adotado no Brasil para o Poder Legislativo, que fortalece a presença de um perfil quase que padronizado, dentro de um modelo que pode ser influenciado, por exemplo, pela relação candidato/vaga, ou pela destinação de votos a partidos e coligações. Sendo assim, a não ascensão de grupos representativos de parcelas menos favorecidas da sociedade na representação do Poder Legislativo é tida como um conjunto de fatores, e não necessariamente atribuída individualmente a um fator ou outro. Nessa lógica, emerge a necessidade de novos estudos que aprofundem a discussão e que possam contribuir com entendimentos ainda mais precisos, no que se diz respeito às razões para os fenômenos ora identificados no presente estudo.

\section{Referências bibliográficas}

AlmeIDA, Jorge. Como vota o brasileiro: perfil ideológico do eleitor e evolução nas pesquisas de opinião de 1994. São Paulo: Xamã, 1998.

BAquero, Marcello. As eleições de 1982 no Rio Grande do Sul num contexto de abertura política. In: BAQUERO, Marcello (org.). Abertura política e comportamento eleitoral: nas eleições de 1982 no Rio Grande do Sul. Porto Alegre: Ed. da Universidade, UFRGS, 1984.

Paradigma de converse: sistemas de crenças e o processo eleitoral em 1982 em POA-RS. Revista do Instituto de Filosofia e Ciências Humanas, POA, v.13, 1985. 
A desilusão democrática: um estudo longitudinal de cultura política. Comunicação \& Política, RJ, CEBELA, v.3, n. 3, 1996.

Novos padrões de comportamento eleitoral: pragmatismo nas eleições municipais de 1996 em Porto Alegre. In: BAQUERo, Marcello (org.) A lógica do processo eleitoral em tempos modernos: novas perspectivas de análise. POA/ Canoas: Editora da Universidade/UFRGS/ Centro Educacional La Salle de Ensino Superior, 1997.

A vulnerabilidade dos partidos políticos e a crise da democracia na América Latina. Porto Alegre: Editora da Universidade/UFRGS, 2000.

BAQUERo, M.; PrÁ, J. R. Matriz histórico-estrutural da cultura política no Rio Grande do Sul e padrões de participação política. Cadernos de Ciência Política, Porto Alegre, no 3, 1995. Série pré-edições.

BragA, M. do S. S.; VeigA, L.F.; Miríade, A. Recrutamento e perfil dos candidatos e dos eleitos à câmara dos deputados nas eleições de 2006. Revista Brasileira de Ciências Sociais, São Paulo, v. 24, n. 70, jun. 2009. Associação Nacional de PósGraduação e Pesquisa em Ciências Sociais - ANPOCS.

BRASIL. Tribunal Superior Eleitoral. Repositório de Dados Eleitorais. Disponível em: <http://www.tse.jus.br/eleicoes/estatisticas/repositorio-de-dados-eleitorais> Acesso em: mai 2013.

CAIN, Bruce; FAREJOHN, John A.; FIORINA, Morris. The personal vote: constituency service and electoral independence. Cambridge, Harvard University Press, 1987.

CARREIRÃo, Y. de S. A eleição presidencial de 2002: uma análise preliminar do processo e dos resultados eleitorais. Revista de Sociologia e Política, Curitiba, n.22, p. 179-194, jun. 2004.

CASTRO, Mônica Mata Machado de. Determinantes do comportamento eleitoral: a centralidade da sofisticação política. RJ: Tese de Doutorado. Instituto Universitário de Pesquisas do Rio de Janeiro, 1994.

De GraziA, Alfred. Public and Republic. New York: Alfred A. Knopf, 1951.

Downs, A. An economic theory of democracy. Nova lorque, Harper \& Row, 1957.

Figueiredo, Marcus A decisão do voto - democracia e nacionalidade, São Paulo, Sumaré/ ANPOCS, 1991.

Fundação JoÃo PInheIRo (FJP). Texto para Discussão 2. Análise do perfil dos representantes eleitos nas assembleias legislativas brasileiras. Publicado em julho de 2013 na página da Escola de Governo Professor Paulo Neves de Carvalho da Fundação João Pinheiro e disponível em: <http://www.eg.fjp.mg.gov.br/index.php/publicacoes/ textos-para-discussao/167-textos-publicados-em-2013/2040-analise-do-perfil-dosrepresentantes-eleitos-nas-assembleias-legislativas-brasileiras>, 2013 a.

Fundação JoÃo PINHEIRo (FJP). Texto para Discussão 3. Análise do perfil dos representantes eleitos nas assembleias legislativas entre 1998 e 2010 na perspectiva das macrorregiões brasileiras. Publicado em dezembro de 2013, na página da Escola de Governo Professor Paulo Neves de Carvalho da Fundação João Pinheiro e disponível em: <http://eg.fjp.mg.gov.br/index.php/docman/publicacoes-2013/57analise-do-perfil-dos-representantes-eleitos-nas-assembleias-legislativas-entre1998-e-2010-na-perspectiva-das-macrorregioes-brasileiras-novo-siteeg>, 2013b. 
FUndAÇÃo JoÃo PINHEIRO (FJP). Análise do perfil dos representantes eleitos nas Assembleias Legislativas entre 1998 e 2010 na perspectiva das Unidades da Federação Brasileira. Relatório final. Belo Horizonte, março 2014.

GoldMAN, M.; SANT'ANA, R. dos S. Elementos para uma análise antropológica do voto. In: PALMeIRA, M.; Goldman, M. (org.) Antropologia, voto e representação política. Rio de Janeiro: Contra Capa, 1996.

KISHLANSKY, Mark A. Parliamentary Selection: social and political choice in early modern England. Cambridge: Cambridge University Press, 1986.

LAVAREDA, A. A democracia nas urnas: o processo partidário eleitoral brasileiro. Rio de Janeiro, Rio Fundo: IUPERJ, 1991.

MAgAlhÃES, Nara Maria Emanuelli. O povo sabe votar: uma visão antropológica. Petrópolis, RJ: Vozes, 1998.

MANSBRIDGE, Jane. Should blacks represent blacks and women represent women? A contingent "yes". Journal of Politics, v. 61, n. 3, p. 628-657, 1999.

Mıguel, Luís Felipe. Impasses da accountability: dilemas e alternativas da representação política. Revista de Sociologia e Política, Curitiba, n. 25, p. 165-175, jun. 2006

MILL, John Stuart. Considerações sobre o governo representativo. Brasília: Editora da Universidade de Brasília, 1981.

Nicolau, Jairo. O sistema eleitoral de lista aberta no Brasil. Dados, v. 49, n. 4, p. 689-718, 2006.

Oliveira, A. Pesquisas, estratégias eleitorais e a disputa presidencial de 2010. Em Debate, Belo Horizonte, v. 2, n. 5, p. 6-11, maio 2010.

PITKIN, Hanna. The concept of representation. Londres: University of California Press, 1967.

PITKIN, Hanna Fenichel. El concepto de representación. Madrid: Centro de Estudios constitucionales, 1985. Tradução de Ricardo Montoro Romero.

RADMANN, Elis Rejane H. O eleitor brasileiro: uma análise do comportamento eleitoral. Dissertação (mestrado em Ciência Política) Universidade Federal do Rio Grande do Sul, Porto Alegre, 2001.

REIS, Fábio W. Consolidação democrática e construção do Estado - notas introdutórias e uma tese. In: ReIS, Fábio W. Reis; O’Donnell, G. (org.), A democracia no Brasil dilemas e perspectivas. São Paulo: Vértice, 1988.

REIS, Fábio W. Conclusão: em busca da lógica do processo eleitoral brasileiro. In: REIS, Fábio Wanderley (org.) Os partidos e o regime: a lógica do processo eleitoral brasileiro. São Paulo: Símbolo, 1978.

RodRIGUES, Leôncio Martins. Partidos, ideologias e composição social: um estudo das bancadas partidárias na Câmara dos Deputados. São Paulo: Editora da Universidade de São Paulo (Edusp), 2002.

SACCHET, Teresa. Representação política, representação de grupos e política de cotas: perspectivas e contendas feministas. Estudos Feministas, Florianópolis, v. 20, n. 2), p. 256, maio-agosto, 2012. 
SIlveIRA, Flávio Eduardo. A decisão do voto no Brasil. Porto Alegre: EDIPUCRS, 1998. SOARES, Gláucio Ary Dillon. Sociedade e política no Brasil: desenvolvimento, classe e política durante a Segunda República. Difusão Européia do Livro, 1973.

URBINATI, Nadia. O que torna a representação democrática? Lua Nova, São Paulo, n. 67, 2006.

Cláudia Júlia Guimarães Horta

Possui doutorado em Demografia pela Universidade Federal de Minas Gerais (2005). Realizou estágio Pósdoutoral na Universidade de Oxford no departamento de Políticas Sociais e Intervenções (2011-2012), Inglaterra. É pesquisadora da Fundação João Pinheiro e professora na Escola de Governo Professor Paulo Neves de Carvalho. Contato: claudia.horta@fjp.mg.gov.br

Simone Cristina Dufloth

Doutora em Ciência da Informação pela Universidade Federal de Minas Gerais (2002). Pesquisadora e professora da Escola de Governo Professor Paulo Neves de Carvalho da Fundação João Pinheiro e Professora titular do Centro Universitário UNA.

Contato: simone.dufloth@fjp.mg.gov.br

Diego Roger Ramos Freitas

Possui mestrado em Administração Pública pela Fundação João Pinheiro (2012). Analista Educacional da Secretaria de Estado de Educação de Minas Gerais. Professor, na Escola de Governo da Fundação João Pinheiro (FJP)

Contato: dierrog@gmail.com 